\title{
Structural and electrochemical properties of nanolayer-stacking structured copper-doped nickel hydroxide
}

\author{
Kyung Ho Kim ${ }^{*}$, Moe Mikami, Yoshio Abe, Midori Kawamura, Takayuki Kiba \\ Department of Materials Science and Engineering, Kitami Institute of Technology, 165 Koen-cho, \\ Kitami, Hokkaido 090-8507, Japan \\ "E-mail: khkim@mail.kitmai-it.ac.jp
}

doi: $10.20964 / 2018.08 .10$

Received: 10 March 2018 / Accepted: 1 May 2018 / Published: 5 July 2018

Copper-doped nickel hydroxide $\left(\mathrm{Cu}: \mathrm{Ni}(\mathrm{OH})_{2}\right)$ was synthesized via a facile wet-chemical method and its structural and electrochemical properties were compared to those of pure nickel hydroxide $\left(\mathrm{Ni}(\mathrm{OH})_{2}\right)$. After $\mathrm{Cu}$ incorporation, the morphology of the $\mathrm{Ni}(\mathrm{OH})_{2}$ nanostructures could be easily tuned from a curved nanolayered structure to a nanolayer-stacking structure. Both samples were hydrophilic. Furthermore, even though no additional conductive and binder materials were employed, the $\mathrm{Cu}: \mathrm{Ni}(\mathrm{OH})_{2}$ sample exhibited better pseudocapacitance performance than the $\mathrm{Ni}(\mathrm{OH})_{2}$ sample. These results confirmed that the $\mathrm{Cu}: \mathrm{Ni}(\mathrm{OH})_{2}$ sample, which can be prepared by an easy low-cost method, shows great potential for application in electrochemical devices.

Keywords: Nickel hydroxide, Copper, Nanolayer-stacking structure, Nanosheets

\section{FULL TEXT}

(C) 2018 The Authors. Published by ESG (www.electrochemsci.org). This article is an open access article distributed under the terms and conditions of the Creative Commons Attribution license (http://creativecommons.org/licenses/by/4.0/). 